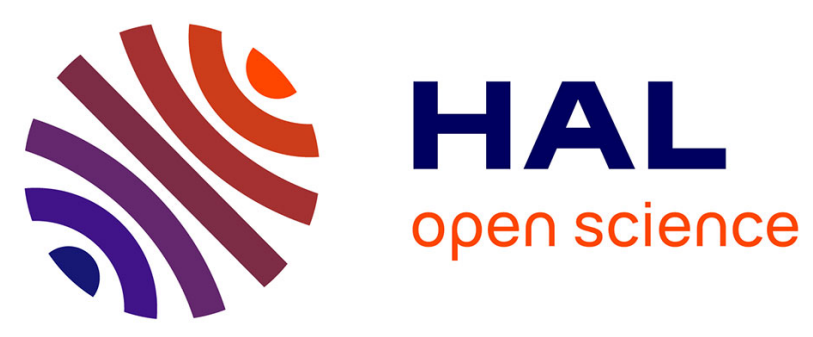

\title{
Near perfect head-to-head selectivity on the supramolecular photocyclodimerisation of 2-anthracenecarboxylate with self-organised gemini surfactant bilayers
}

Wijak Yospanya, Masaki Nishijima, Yasuyuki Araki, Thierry Buffeteau, Emilie Pouget, Takehiko Wada, Reiko Oda

\section{To cite this version:}

Wijak Yospanya, Masaki Nishijima, Yasuyuki Araki, Thierry Buffeteau, Emilie Pouget, et al.. Near perfect head-to-head selectivity on the supramolecular photocyclodimerisation of 2anthracenecarboxylate with self-organised gemini surfactant bilayers. Chemical Communications, 2020, 56 (69), pp.10058-10061. 10.1039/d0cc04198j . hal-03002147

HAL Id: hal-03002147

https://hal.science/hal-03002147

Submitted on 27 Nov 2020

HAL is a multi-disciplinary open access archive for the deposit and dissemination of scientific research documents, whether they are published or not. The documents may come from teaching and research institutions in France or abroad, or from public or private research centers.
L'archive ouverte pluridisciplinaire HAL, est destinée au dépôt et à la diffusion de documents scientifiques de niveau recherche, publiés ou non, émanant des établissements d'enseignement et de recherche français ou étrangers, des laboratoires publics ou privés. 
Near perfect head-to-head selectivity on supramolecular photocyclodimerisation of 2anthracenecarboxylate with self-organised gemini surfactant bilayers

Wijak Yospanya,ab Masaki Nishijima,b Yasuyuki Araki,b Thierry Buffeteau,c Emilie Pouget,a Takehiko Wada, ${ }^{*}$ b and Reiko Oda*a

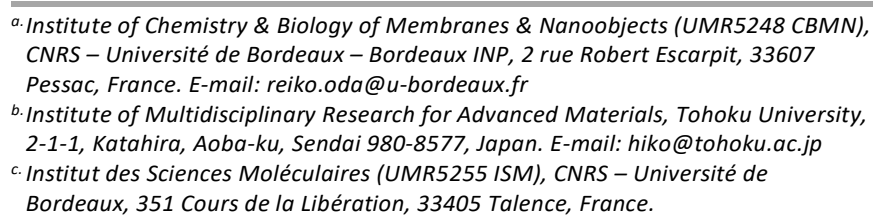

Silicificated self-organised crystalline bilayers of gemini surfactants were used as reaction templates for supramolecular regioselective [4+4] photocyclodimerisation of 2-anthracenecarboxylate in water. Near perfect head-to-head cyclodimers selectivity, up to $97 \%$ at room temperature was achieved with accelerated dimerisation.

Ever since the first report in $1867,{ }^{1-3}$ the [4+4] photocyclodimerisation of anthracene and its derivatives has attracted much attention due to the unique structure and properties of the photocyclodimers obtained, and has been employed indeed as a key motif in energy storage and photoreversible devices. ${ }^{4-8}$ However, controlling regio- and enantioselectivities of the photocyclodimerisation of anthracene derivatives, such as 2anthracenecarboxylate (AC) (Scheme 1), is a challenge, which has driven researchers to the use of supramolecular approach, ${ }^{9,10}$ using cyclodextrins, ${ }^{11-14}$ proteins, ${ }^{15,16}$ molecular templates, ${ }^{17-21}$ molecular cages, ${ }^{20-}$ ${ }^{22}$ twisted self-associated templates, ${ }^{18}$ organogels, ${ }^{23}$ and helical metal nanostructures ${ }^{24}$ as hosts and templates. Most of the reported systems, however, require the multi-step synthesis of host/template, the modification of guest substrate and/or the irradiation in organic media at low temperature. From the Sustainable Development Goals (SDGs) point of view, a readily accessible, spontaneously self-organisable, operative under ambient conditions, yet biodegradable host/template is advocated, while a three-dimensionally well-defined, appropriately functionalised, structurally robust host/template is essential for directing the stereochemical course of photoreaction to desired product(s). Upon photoirradiation in aqueous media, AC form anti- and syn-isomeric head-to-tail (HT) cyclodimers (ACD1 and ACD 2) and head-to-head (HH) cyclodimers (ACD 3 and ACD 4) in a 4:1 ratio (Table 1, entry 1) for steric and electrostatic reasons. Possessing two functional groups on the same side of molecule, the $\mathrm{HH}$ cyclodimers are structurally attractive as building blocks for functional devices and materials. ${ }^{25,26}$ Wolff et al. succeeded to increase the $\mathrm{HH} / \mathrm{HT}$ ratio of the photo-cyclodimerisation of 9-substituted anthracenes by executing the reaction in cationic and anionic micelles to gain modestly enhanced $\mathrm{HH} / \mathrm{HT}$ ratios of $0.62-0.76,{ }^{27,28}$ for which the flexible micelle shell would be responsible for the limited value of $\mathrm{HH} / \mathrm{HT}$ ratios.

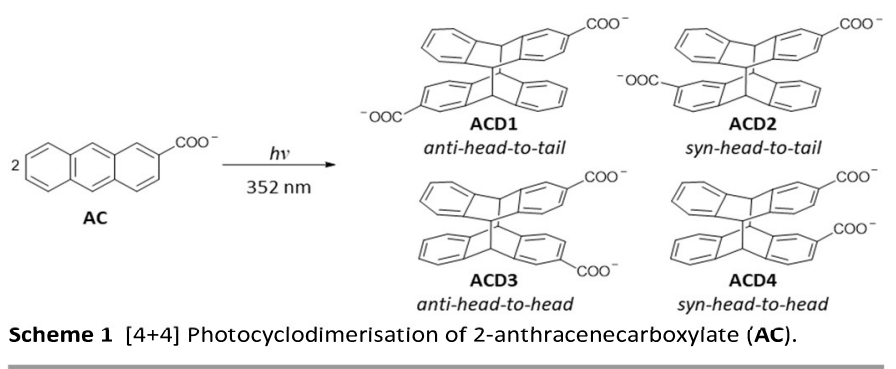


Previously, we have reported the self-organisation of enantiopure tartrate with gemini-type cationic surfactant, $N, N^{\prime}-$ dihexadecyl- $N, N, N^{\prime}, N^{\prime}$-tetramethylethylene diammonium (hereafter abbreviated as 16-2-16). Mixing 16-2-16 with L- or Dtartrate in water or some organic solvents leads to the formation of right- or left-twisted double-bilayer crystalline structures termed nanoribbons (NRs). ${ }^{29}$ These chiral NRs derived from 16-2-16 and tartrate are transcribed into a silica matrix using tetraethyl orthosilicate (TEOS) ${ }^{30,31}$ to form hybrid silica-organic composites (Figure 1).

These hybrid NRs can be used as chiral scaffolds for organising achiral anions (from simple halides to anionic dyes) and inducing chiroptical responses. The chiral inductor tartrate is exchangeable with other anions without deteriorating the chiral supramolecular organisation of gemini surfactants. ${ }^{32,33}$ This result indicates that the silica nanohelical framework is structurally robust enough to keep the memory of 16-2-16 chirality throughout the anion exchange process. Furthermore, the hybrid NRs are stable in water at room temperature in the concentration range of $10^{-4}$ to $10^{-2} \mathrm{M}$, and isolable through filtration or centrifugation without affecting their chiroptical properties.

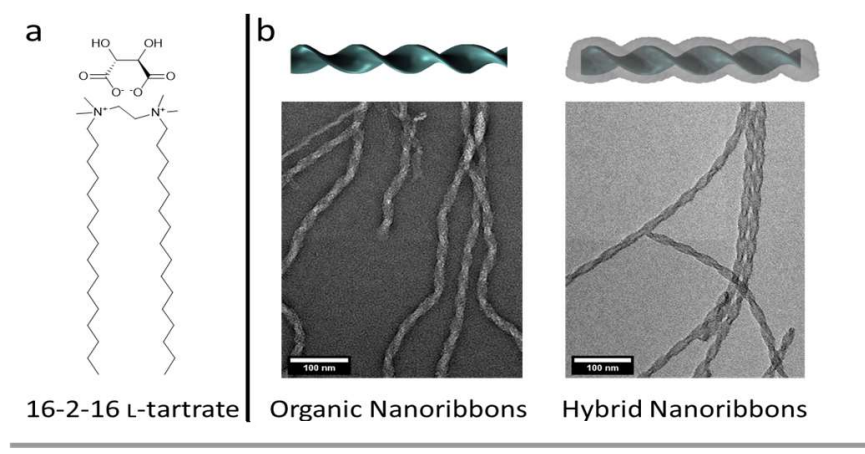

Figure 1 (a) Molecular structure of 16-2-16 L-tartrate and (b) twisted morphology of self-assemblies in water before and after silica transcription.

In the present study, monoanionic AC exchanged with tartrate inside the hybrid NRs silica walls was employed as photosubstrate in the presence of 16-2-16 bilayers, photoirradiation of which formed the HH cyclodimers with $97 \%$ selectivity.

Hybrid NRs of 16-2-16 tartrate were prepared as described previously. ${ }^{31,34}$ Briefly, 16-2-16 L- or D-tartrate (1.0 $\mathrm{mM}$ ) was dissolved in ultra-pure water $(5 \mathrm{~mL})$ by heating to $70^{\circ} \mathrm{C}$; the resulting solution was cooled down to $20^{\circ} \mathrm{C}$ and kept at that temperature for $1 \mathrm{~h}$, to which was added $5 \mathrm{~mL}$ of a TEOS $(5 \% \mathrm{v} / \mathrm{v})$ solution pre-hydrolysed for $5 \mathrm{~h}$ in $0.1 \mathrm{mM}$ aqueous tartaric acid. The mixture was placed in a vial which was rotated for $14 \mathrm{~h}$ at $20^{\circ} \mathrm{C}$ on a roller mixer. The hybrid NRs thus obtained were washed with ultra-pure water at $4{ }^{\circ} \mathrm{C}$ to remove the excess TEOS without damaging the nanostructure of 16-2-16 tartrate inside the silica insulate, and stored at $4{ }^{\circ} \mathrm{C}$. As can be seen from the TEM images in Figure 1b, the hybrid NRs structure was well preserved in the prepared sample. The content of 16-2-16 tartrate in the hybrid silica-organic nanostructures was reported to be ca. $30 \% \mathrm{w} .{ }^{35}$

Upon addition of AC to the 16-2-16 tartrate in the hybrid NR thus prepared, the 0-0 transition of the $L_{b}$ band of $A C$ at $387 \mathrm{~nm}$ was red-shifted to $394 \mathrm{~nm}$ (Figure S2a), indicating the J-aggregation of AC inside the hybrid NRs produced. ${ }^{36-38}$ Also in the case of L-hybrid NRs, a strong positive couplet, implying the righthanded screw arrangement of the AC chromophores in the hybrid NRs, gradually developed at the $B_{b}$ band, the amplitude of which reached a plateau in $5 \mathrm{~h}\left(20^{\circ} \mathrm{C}\right)$ to $10 \mathrm{~h}\left(4^{\circ} \mathrm{C}\right)$ (Figure S2C). The contribution of linear dichroism (LD) turned out to be negligible (Figure S4) under the conditions employed. ${ }^{39} \mathrm{In}$ the case of $\mathrm{L-}$ hybrid NRs, anisotropy $(g)$ factors at the extrema amounted to 7.5 and $-6.2 \times 10^{-3}$ at 238 and $230 \mathrm{~nm}$, respectively. The opposite signs $C D$ signals were observed with D-hybrid NRs. It is important to note that if the tartrates in NRs were fully exchanged, the stoichiometry of AC (monoanion) to 16-2-16 (dication) should be 2:1 to balance the charge (Figure S11). However, the circular dichroism (CD) intensity reaches the maximum at the stoichiometric 1:1 ratio (Figure 2), meaning that only half of the tartrates were replaced by AC. This behaviour differs from the results reported previously for methyl orange and halides. ${ }^{40}$ Our previous study has shown that the self-organised double-bilayer assembly of 16-2-16 tartrate possesses inner and outer tartrate layers in equal quantities. ${ }^{40}$ (Figure 2, top left) Considering such a double bilayer structure, we deduce that only the outer-layer tartrates are exchanged by AC, while the inner-layer tartrates stay intact. 
However, over the 1 to 1 ratio, AC will start to exchange with inner-layer tartrate (Figure 2 top right). Not only $\mathrm{AC}$ has a bulky and rigid structure, due to the strong stacking interaction of $\mathrm{ACs}$, they tend to make dianionic pairs which have similar affinity to gemini bilayer as tartrate. Such aggregates are difficult to go through the crystalline gemini layer and exchange with inner-layer tartrates.

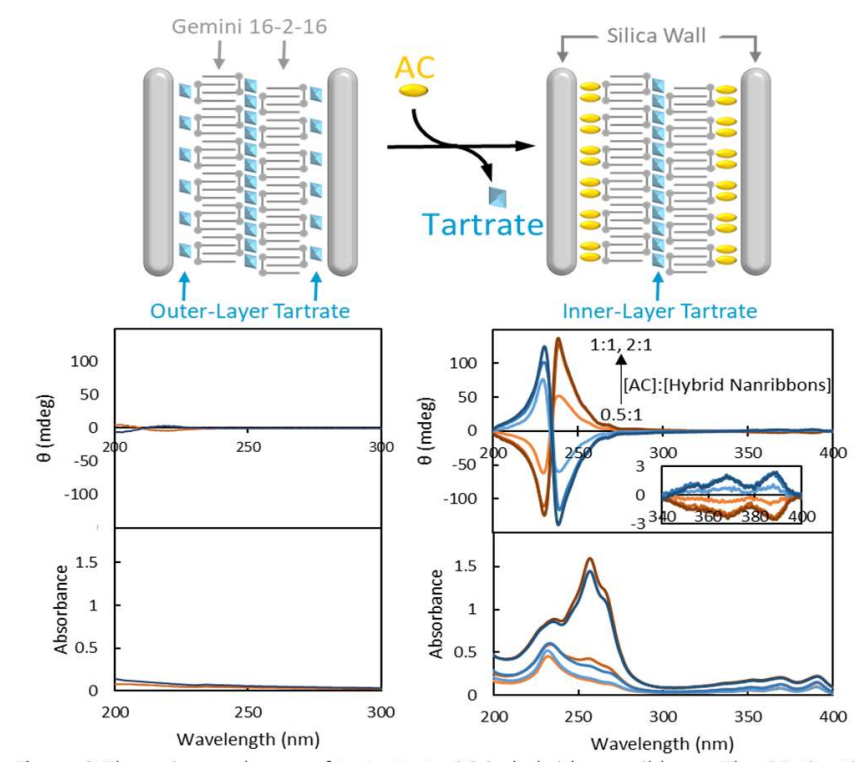

Figure 2 The anion exchange of tartrate to $\mathrm{AC}$ in hybrid nanoribbons. The CD titration was conducted with the fixed [hybrid nanoribbons] $(25 \mu \mathrm{M})$ and varied $[\mathbf{A C}](13,25$ and $50 \mu \mathrm{M})$. The ICD reaches the maximum $\left(7.5\right.$ and $\left.-6.2 \times 10^{-3}\right)$ at $25 \mu \mathrm{M}$, which corresponds to $\mathbf{A C}$ to hybrid nanoribbons 1 to 1 ratio. At 2 to 1 , the absorption at $258 \mathrm{~nm}$ corresponding to free $\mathbf{A C}$ in solution appears. The ICD can be observed throughout the AC spectrum up to $400 \mathrm{~nm}$. LD components were small enough to be neglected.

To elucidate the photophysical, as well as the photochemical, consequences of AC stacking in hybrid NRs, we compared the fluorescence spectrum of $A C(10 \mu \mathrm{M})$ incorporated in hybrid NRs $(10 \mu \mathrm{M})$ with that of free $\mathbf{A C}(10 \mu \mathrm{M})$ in the bulk solution. As shown in Figure $3 a$ and $3 b$, upon hybridisation with NR, AC fluorescence was significantly quenched (by a factor of 7.2), hypsochromically shifted (by ca. $5 \mathrm{~nm}$ ) and band-sharpened exhibiting the vibrational fine structures, all of which can be explained by the change from polar to nonpolar local environment around the $\mathbf{A C}$ molecules incorporated in NR. ${ }^{41}$ It is to note that the fluorescence intensity of hybrid NR rapidly faded out upon repeated measurements with a $30 \%$ reduction after 10 scans, while essentially no fading $(<1 \%)$ was observed for free $\mathbf{A C}$ even after 30 scans under the same conditions (Figure $3 \mathrm{c}$ and $3 \mathrm{~d}$ ). This probably indicates that the stacking structure of $A C$ in hybrid NR and/or the increased local concentration of $A C$ are inherently favourable for photocyclodimerisation. The progress of photoreaction was fluorometrically monitored and the results were analysed by the pseudo-first order kinetics, assuming that the concentration of excited-state $\mathbf{A C}$ is much lower than that of ground-state $\mathbf{A C}{ }^{42}$ The $\mathbf{A C}$ consumption rate, constant upon photoirradiation of $\mathbf{A C}$ in hybrid NRs $(10 \mu \mathrm{M})$, was $21 \mathrm{M}^{-1}$ $\mathrm{s}^{-1}$, which is 77 -fold larger than that for free $\mathrm{AC}\left(0.27 \mathrm{M}^{-1} \mathrm{~s}^{-1}\right)$ (Figure S10). 


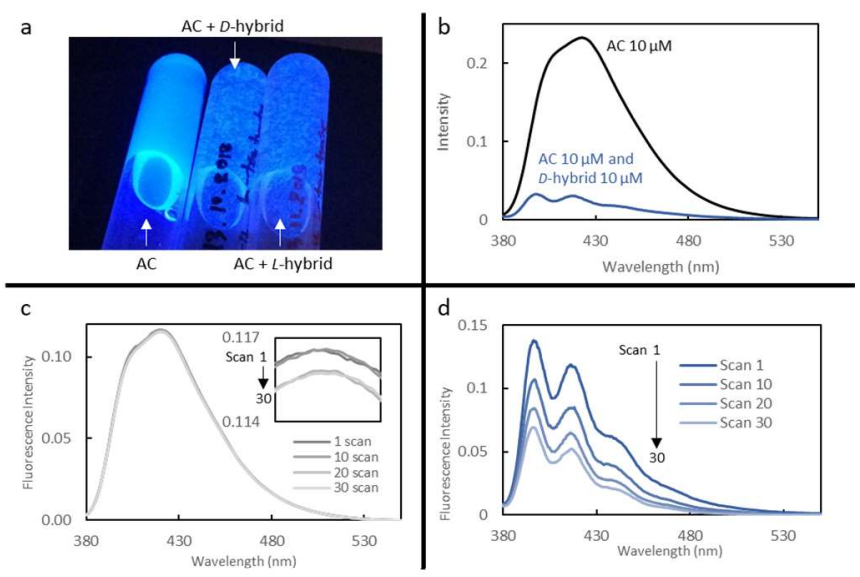

Figure 3 (a) The fluorescence of $A C(100 \mu \mathrm{M})$ with and without hybrid nanoribbons $(100 \mu \mathrm{M})$ observed under $352 \mathrm{~nm}$ UV lamp. (b) The fluorescence emission spectra of $A C(10 \mu \mathrm{M})$ with and without D-hybrid nanoribbons (10 $\mu \mathrm{M})$ emission spectra of AC (10 $\mu \mathrm{M})$ with and without D-hybrid nanoribbons $(10 \mu \mathrm{M})$ (JASCO CPL-300, ex $350 \mathrm{~nm}$, ex and em bandwidth $10 \mathrm{~nm}$, detector HT $800 \mathrm{~V}$. (c) The fluorescence emission spectra of AC $10 \mu \mathrm{M}$ after multiple scans (JASCO CPL 300 , ex $350 \mathrm{~nm}$, ex and em bandwidth $10 \mathrm{~nm}$, scan speed $100 \mathrm{~nm} / \mathrm{s}$, detector $\mathrm{H}$ $700 \mathrm{~V})$. (d) The fluorescence emission spectra of AC $(10 \mu \mathrm{M})$ with D-hybrid nanoribbons $(10 \mu \mathrm{M})$ after multiple scans (the same parameters as (c), except for the detector HT $850 \mathrm{~V}$ ).

For the purpose of product analysis, a $10 \mathrm{~mL}$ solution of AC $(0.1 \mathrm{mM})$ and 16-2-16 D- or L-tartrate hybrid NRs $(0.1$ $\mathrm{mM}$ ) was incubated overnight at $4{ }^{\circ} \mathrm{C}$ and then photoirradiated with an 8-W UV-A fluorescent lamp (Ushio F8T5BL) at $4{ }^{\circ} \mathrm{C}$ on a roller mixer. Despite the low lamp power, the fluorescence of the suspended NR sample faded out after $1 \mathrm{~h}$ of irradiation, indicating highly efficient photocyclodimerisation.

To analyse the relative yield and enantiomeric excess (ee) of each ACD, the organic components of hybrid NRs (16-2-16, tartrate, AC and ACD) were extracted from silica nanostructures by hot methanol. The extracted solution was dried, re-dissolved in a 1:1 (v/v) mixture of acetonitrile and aqueous $\mathrm{NaOH}(1 \mathrm{mM})$ and then filtered. The filtrate was analysed by chiral HPLC following the reported protocols to give the product distribution and ee listed in Table 1.

Table 1 Supramolecular photocyclodimerisation of AC in hybrid nanoribbon derived from silificated 16-2-16 D- or L-tartrate in aqueous solution ${ }^{a}$

\begin{tabular}{|c|c|c|c|c|c|c|c|c|c|c|c|c|c|c|}
\hline \multirow[b]{2}{*}{ Entry } & \multirow[b]{2}{*}[\mathrm{AC}]{$/ \mu \mathrm{M}$} & \multirow[b]{2}{*}[NR]{$/ \mu \mathrm{M}$} & \multirow{2}{*}{$\begin{array}{l}\text { Tartrate } \\
\text { chirality }\end{array}$} & \multicolumn{2}{|c|}{ Incubation } & \multicolumn{2}{|c|}{ Irradiation } & \multicolumn{4}{|c|}{ Product distribution/\% } & \multirow[b]{2}{*}{$\% \mathrm{HH}$} & \multicolumn{2}{|c|}{ ee/\% } \\
\hline & & & & $\begin{array}{l}\text { Tempera } \\
\text { ture } /{ }^{\circ} \mathrm{C}\end{array}$ & Period/h & $\begin{array}{c}\text { Tempera- } \\
\text { ture } /{ }^{\circ} \mathrm{C}\end{array}$ & Period/h & ACD1 & ACD2 & ACD3 & ACD4 & & ACD2 & ACD3 \\
\hline $1^{b}$ & 30 & 0 & $c$ & c & c & $\sim 25$ & 0.17 & 43 & 38 & 12 & 7 & 19 & -0.4 & -0.7 \\
\hline $2^{d}$ & 100 & 100 & $\mathrm{~L}$ & 4 & overnight & 4 & 1 & $1 \pm 1$ & $2 \pm 1$ & $53 \pm 2$ & $44 \pm 2$ & $97 \pm 1$ & $e$ & $-2.3 \pm 1.4$ \\
\hline $3^{d}$ & & & $D$ & 4 & overnight & 4 & 1 & $1 \pm 1$ & $2 \pm 1$ & $54 \pm 2$ & $43 \pm 1$ & $97 \pm 1$ & $e$ & $-2.3 \pm 0.9$ \\
\hline 4 & 10 & 500 & $\mathrm{~L}$ & 4 & overnight & 4 & 1 & 1 & 4 & 56 & 39 & 95 & $e$ & -9.5 \\
\hline 5 & 100 & 100 & L & 4 & 0 & 4 & 1 & 5 & 10 & 46 & 39 & 85 & -1.4 & -0.6 \\
\hline 6 & & & & & 1 & 4 & 1 & 10 & 13 & 31 & 46 & 77 & 0.1 & -2.9 \\
\hline 7 & & & & & overnight & 4 & 1 & 1 & 2 & 53 & 44 & 97 & $e$ & -2.3 \\
\hline 8 & & & & & & -20 & 1.5 & $e$ & 2 & 35 & 63 & 98 & $e$ & -0.5 \\
\hline 9 & & & & 20 & 1 & 4 & 1 & 2 & 2 & 53 & 43 & 96 & $e$ & -5.6 \\
\hline 10 & & & & $\sim 25$ & 3 & $\sim 25$ & 3.5 & 1 & 2 & 55 & 42 & 97 & $e$ & -0.4 \\
\hline
\end{tabular}

${ }^{a}$ Sample solution $\left(10 \mathrm{~mL}\right.$ ) placed in a vial was continuously rotated on a roller mixer during the irradiation at $352 \mathrm{~nm}$ with an 8 -W UV-A fluorescent lamp. ${ }^{b}$ Carried out in phosphate buffer ( $\mathrm{pH} 7$ ) using 500-W Hg-Xe lamp with glass filter (Toshiba, $>350 \mathrm{~nm}$ ). ${ }^{c}$ Not applicable. ${ }^{d}$ Average of 3 independent runs with standard deviation. e Not determined due to low yield.

Beyond our anticipation, a very high HH selectivity of $97 \%(53 \pm 2 \%$ ACD3 and $44 \pm 2 \%$ ACD4) was obtained with an excellent reproducibility upon irradiation of AC incorporated in the NR that was derived from 16-2-16 and L-tartrate and incubated overnight at $4{ }^{\circ} \mathrm{C}$ (Table 1, entry 2). Similar HH selectivity with a comparable ACD3:ACD4 ratio of 54:43 (entry 3) was observed with 16-2-16 D-tartrate NRs. Changing the molar ratio of AC versus NR from the standard $1: 1$ to $1: 5$ did not affect strongly the product distribution, leading to a $95 \% \mathrm{HH}$ selectivity and a similar ACD3:ACD4 ratio of 56:39 (Table 1, entry 4). 
However, the incubation temperature and period as well as the irradiation temperature turned out to be critical for the product distribution. The $1 \mathrm{~h}$ incubation prior to photoirradiation was enough at $20^{\circ} \mathrm{C}$ to yield a $96 \% \mathrm{HH}$ selectivity, while the incubation overnight was needed at $4{ }^{\circ} \mathrm{C}$ to gain a similar $\mathrm{HH}$ selectivity (Table 1, entry 9). These results are consistent with the faster evolution of ICD signals, indicating faster exchange at $20^{\circ} \mathrm{C}$ than at $4{ }^{\circ} \mathrm{C}$ (Figure S2). The $\mathrm{HH}$ selectivity remained high at $98 \%$ also upon irradiation in aqueous acetone at $-20^{\circ} \mathrm{C}$, but the ACD3:ACD4 ratio was reduced to $35: 68$, probably both due to the temperature and solvent effects. To the best of our knowledge, such near perfect $\mathrm{HH}$ selectivity in water at room temperature has never been reported previously. Most of the high $\mathrm{HH}$ selectivities are reported for the photocyclodimerisations conducted in solid state or in organic solvents at low temperatures. ${ }^{12,17,24}$ Yang et al. also reported an equally high $97 \% \mathrm{HH}$ selectivity, but for the photocyclodimerisation of AC covalently attached to $\alpha$ cyclodextrin. ${ }^{43}$

In keen contrast to the high regioselectivity discussed above, the enantioselectivity was disappointingly low for the NRmediated photocyclodimerisation of AC, affording nearly racemic ACD3 (0-6\% ee) at least under the conditions employed (Table 1). This somewhat unexpected result, together with varied ACD3:ACD4 ratio, would be rationalised by the following scenario: (1) AC molecules replace L- or D-tartrate templates in silificated chiral NR through ion-pairing of AC's carboxylate with 16-2-16's ammonium group. AC molecules are stacked to each other to form a right- or left- handed screw and therefore exhibit a UV-Vis bathochromic shift and a strong positive CD couplet at the main band of AC; (2) However, the $p K_{a}$ of 2anthracenecarboxylic acid $(\mathbf{A C H})$ is significantly augmented from 4.2 to 6.6 upon photoexcitation, ${ }^{44}$ meaning that excited $\mathbf{A C}$ anion is readily protonated in the less polar environment of NR and becomes free from the ion-pairing with 16-2-16's ammonium group; (3) Nevertheless, the liberated AC is not totally free. It is still confined in the same nanospace with some rotational freedoms around the long molecular axis, which spoil the enantiotopic face selectivity attained upon adsorption to the chiral NR. Yet, the longitudinal rotation around the short molecular axis, requiring more space, is not allowed and hence the $\mathrm{HH}$ selectivity is kept high even upon photoexcitation.

In the present system, the silica shell and the crystalline double-bilayer structure of 16-2-16 cooperatively act as a semi-rigid framework to organise and bind $\mathbf{A C}$ along the chiral surface in-between the two during the photocyclodimerisation reaction. The silica framework reinforces the confinement of the double bilayers within the chiral nanospace, forcing them to be tightly organised. Such a crystalline organisation of the template with directional anisotropy leading mostly to $\mathrm{HH}$ dimers is different from the usual dynamic and flexible surfactant assemblies. ${ }^{45}$ Indeed, the use of such hybrid NR is a promising sustainable supramolecular photochemical reaction template. In addition, the chirality induction and conservation of hybrid NR make it a potential chiral template of enantioselective reactions. We are currently working on the asymmetric synthesis using hybrid NR as a chiral template.

By employing the [4+4] photocyclodimerisation of AC as a model reaction, we have demonstrated that the hybrid NR functions as a stereocontrolling, yet rate-accelerating, reaction template to afford the $\mathrm{HH}$ dimers in excellent selectivities of up to $97 \%$ in water at room temperature. The enantioselectivity was not satisfactory at all, which however provides us with invaluable insights into the detailed binding and reaction mechanisms as well as the design principles for better hosts and more suitable guest substrates. The results and concept obtained in this study show a high potential of the hybrid NR as a sustainable supramolecular regioselective nanoreactor.

This work was supported by the Centre National de la Recherche Scientifique and Universite de Bordeaux in the context of France-Japan International Associated Laboratory (LIA-CNPA). This work was supported in part by "Five-star Alliance," and JSPS Grant-in-Aid for Scientific Research (A), T.W. W.Y. thanks the Sato-Yo international scholarship foundation for his research fellowship.

\section{Conflicts of interest}

There are no conflicts to declare.

\section{Notes and references}

1 J. Fritzsche, J. Prakt. Chemie, 1867, 101, 333-343.

2 F. D. Greene, S. Leslie Misrock and J. R. Wolfe, J. Am. Chem. Soc., 1955, 77, 3852-3855.

3 H. D. Becker, Chem. Rev., 1993, 93, 145-172.

4 Z. Jiang, M. L. Tan, M. Taheri, Q. Yan, T. Tsuzuki, M. G. Gardiner, B. Diggle and L. A. Connal, Angew. Chemie - Int. Ed., 2020, 59, 70497056.

5 P. G. Frank, B. T. Tuten, A. Prasher, D. Chao and E. B. Berda, Macromol. Rapid Commun., 2014, 35, 249-253. 
6 B. Fabre, D. M. Bassani, C. K. Liang, S. Lhenry and P. Hapiot, J. Phys. Chem. C, 2013, 117, 12725-12734.

7 G. Ganguly, M. Sultana and A. Paul, J. Phys. Chem. Lett., 2018, 9, 328-334.

8 M. Tu, H. Reinsch, S. Rodríguez-Hermida, R. Verbeke, T. Stassin, W. Egger, M. Dickmann, B. Dieu, J. Hofkens, I. F. J. Vankelecom, N. Stock and R. Ameloot, Angew. Chemie - Int. Ed., 2019, 58, 2423-2427.

9 N. Vallavojua and J. Sivaguru, Chem. Soc. Rev., 2014, 43, 4084-4101.

10 B.C.Pemberton, R.Raghunathan, N. Vallavojua and J. Sivaguru, Chem. Eur. J., 2012, 18, 12178-12190.

11 T. Tamaki, Chem. Lett., 1984, 13, 53-56.

12 T. Tamaki, T. Kokubu and K. Ichimura, Tetrahedron, 1987, 43, 1485-1494.

13 C. Yang, G. Fukuhara, A. Nakamura, Y. Origane, K. Fujita, D. Q. Yuan, T. Mori, T. Wada and Y. Inoue, J. Photochem. Photobiol. A Chem., 2005, 173, 375-383.

14 J. Yao, Z. Yan, J. Ji, W. Wu, C. Yang, M. Nishijima, G. Fukuhara, T. Mori and Y. Inoue, J. Am. Chem. Soc., 2014, 136, 69166919.

15 M. Nishijima, M. Goto, M. Fujikawa, C. Yang, T. Mori, T. Wada and Y. Inoue, Chem. Commun., 2014, 50, $14082-14085$.

16 A. Nakamura and Y. Inoue, J. Am. Chem. Soc., 2003, 125, 966-972.

17 Y. Kawanami, S. Y. Katsumata, M. Nishijima, G. Fukuhara, K. Asano, T. Suzuki, C. Yang, A. Nakamura, T. Mori and Y. Inoue, J. Am. Chem. Soc., 2016, 138, 12187-12201.

18 A. Urushima, D. Taura, M. Tanaka, N. Horimoto, J. Tanabe, N. Ousaka, T. Mori and E. Yashima, Angew. Chemie - Int. Ed., 2020, 59, 7478-7486.

19 M. M. Maturi, G. Fukuhara, K. Tanaka, Y. Kawanami, T. Mori, Y. Inoue and T. Bach, Chem. Commun., 2016, 52, 10321035.

20 M. Alagesan, K. Kanagaraj, S. Wan, H. Sun, D. Su, Z. Zhong, D. Zhou, W. Wu, G. Gao, H. Zhang and C. Yang, J. Photochem. Photobiol. A Chem., 2016, 331, 95-101.

21 X. Wei, A. M. Raj, J. Ji, W. Wu, G. B. Veerakanellore, C. Yang and V. Ramamurthy, Org. Lett., 2019, 21, 7868-7872.

22 V. Ramamurthy and J. Sivaguru, Chem. Rev., 2016, 116, 9914-9993.

23 A. Dawn, N. Fujita, S. Haraguchi, K. Sada and S. Shinkai, Chem. Commun., 2009, 7345, 2100-2102.

24 X. Wei, J. Liu, G.-J. Xia, J. Deng, P. Sun, J. J. Chruma, W. Wu, C. Yang, Y.-G. Wang and Z. Huang, Nat. Chem., 2020, 12, 551-559.

25 A. B. Grommet, M. Feller and R. Klajn, Nat. Nanotechnol., 2020, 15, 256-271.

26 J. Leblond and A. Petitjean, ChemPhysChem, 2011, 12, 1043-1051.

27 T. Wolff and N. Müller, J. Photochem., 1983, 23, 131-140.

28 A. Schütz and T. Wolff, J. Photochem. Photobiol. A Chem., 1997, 109, 251-258.

29 R. Oda, I. Huc and S. J. Candau, Chem. Commun., 1997, 2105-2106.

30 K. Sugiyasu, S. I. Tamaru, M. Takeuchi, D. Berthier, I. Huc, R. Oda and S. Shinkai, Chem. Commun., 2002, 2, 1212-1213.

31 T. Delclos, C. Aimé, E. Pouget, A. Brizard, I. Huc, M. H. Delville and R. Oda, Nano Lett., 2008, 8, 1929-1935.

32 N. Ryu, Y. Okazaki, K. Hirai, M. Takafuji, S. Nagaoka, E. Pouget, H. Ihara and R. Oda, Chem. Commun., 2016, 52, 58005803.

33 Y. Okazaki, N. Ryu, T. Buffeteau, S. Pathan, S. Nagaoka, E. Pouget, S. Nlate, H. Ihara and R. Oda, Chem. Commun., 2018, 54, 1024410247.

34 Y. Okazaki, J. Cheng, D. Dedovets, G. Kemper, M. H. Delville, M. C. Durrieu, H. Ihara, M. Takafuji, E. Pouget and R. Oda, ACS Nano, 2014, 8, 6863-6872.

35 Y. Okazaki, N. Ryu, T. Buffeteau, S. Pathan, S. Nagaoka, E. Pouget, S. Nlate, H. Ihara and R. Oda, Chem. Commun., 2018, 54, 1024410247.

36 J. E. Anthony, Chem. Rev., 2006, 106, 5028-5048.

37 T. Hinoue, Y. Shigenoi, M. Sugino, Y. Mizobe, I. Hisaki, M. Miyata and N. Tohnai, Chem. - A Eur. J., 2012, 18, 4634-4643.

38 M. L. Waters, Curr. Opin. Chem. Biol., 2002, 6, 736-741.

39 Y. Shindo and Y. Ohmi, J. Am. Chem. Soc., 1985, 107, 91-97.

40 R. Oda, F. Artzner, M. Laguerre and I. Huc, J. Am. Chem. Soc., 2008, 130, 14705-14712.

41 M. Nishijima, T. Wada, T. Mori, T. C. S. Pace, C. Bohne and Y. Inoue, J. Am. Chem. Soc., 2007, 129, 3478-3479.

42 J. A. K. du Plessis and J. S. Viljoen, J. Mol. Catal. A. Chem., 1995, 99, 71-76.

43 C. Yang, T. Mori and Y. Inoue, J. Org. Chem., 2008, 73, 5786-5794.

44 E. Vander Donckt and G. Porter, Trans. Faraday Soc., 1968, 64, 3215-3217.

45 V. K. Sharma, S. Mitra and R. Mukhopadhyay, Langmuir, 2019, 35, 14151-14172. 